\title{
Promotion of Maple Bridge Experience in Guangdong-Hong Kong-Macau Grand Bay Area under the Background of Non-Unitary System
}

\author{
Ying Ren \\ Green Development Law Research Center, Guangdong University of Foreign Studies, Guangzhou, China \\ Email:2052614426@qq.com
}

How to cite this paper: Ren, Y. (2019) Promotion of Maple Bridge Experience in Guangdong-Hong Kong-Macau Grand Bay Area under the Background of Non-Unitary System. Open Journal of Social Sciences, 7 , 85-94.

https://doi.org/10.4236/jss.2019.74008

Received: March 21, 2019

Accepted: April 9, 2019

Published: April 12, 2019

Copyright $\odot 2019$ by author(s) and Scientific Research Publishing Inc. This work is licensed under the Creative Commons Attribution International License (CC BY 4.0).

http://creativecommons.org/licenses/by/4.0/

\begin{abstract}
The Maple Bridge experience should be based on the national and regional reality of the new era in order to realize innovative development. The deep integration development of Guangdong, Hong Kong and Macao is an important opportunity to break the dilemma of harmonious governance between the mainland and Hong Kong and Macao. In order to solve the legal problems of promoting the experience of Maple Bridge under different legal sources and economic and social backgrounds, we should promote the integration and development of the folk norms of Guangdong, Hong Kong and Macao under the background of non-unitary system. Aiming at regional stability, we can release the non-institutionalized civil contract and the efficiency of trade rules governance, and form an effective link mechanism from information sharing, public participation to interest coordination, and deep cooperation.
\end{abstract}

\section{Keywords}

Maple Bridge Experience, Non-Unitary System, Guangdong-Hong Kong-Macau Grand Bay Area

\section{The Origin and Development of Maple Bridge Experience}

Maple Bridge experience was created by cadres and masses in Fengqiao Town of Zhuji City in the early 1960s in Zhejiang Province. The core content of Maple Bridge experience is the local solution of contradictions. It is the way of resolving contradictions and disputes, and is also an important embodiment of carrying out the mass line of the Party. Popularizing Maple Bridge experience with 
innovative thinking has become an important issue in resolving social conflicts and maintaining social stability in the new period. And localized dispute settlement mode brings new ideas to regional problem solving under the background of non-single system. However, under the background of the cross-law system, the popularization of Maple Bridge experience needs to be based on the particularity of the governance of the Bay Area and the main problems faced, so as to realize the adaptability and innovative development.

\subsection{The Perspective of Combination of National Strategy and Local Practice}

In the Bay Area, Maple Bridge experience lays a practical foundation for dealing with the relationship between the country and the local places with the local solution of contradictions. Under the background of socialism with Chinese characteristics in the new era, the execution of the experience of the Maple Bridge is faced with special situation, which means it is necessary to combine the national strategy with the local practice to promote the innovative transformation and creative development of the experience of the Maple Bridge. Forming the new experience of the Maple Bridge with distinctive characteristics of the times is the important task of adhering to and carrying out the Party mass line in the new era. Among them, the Maple Bridge experience in Guangdong-Hong Kong-Macau Grand Bay Area is the most special, and its promotion in the Bay area has the most significant impact on the regional stability and development. In the Bay Area, the Maple Bridge experience remolds the "geographical relationship" based on the social order through the bottom-up path of development to achieve self-management with the background of three different law systems. Its core characteristics are life, popularity, spontaneity, implementation and operation. During the revolutionary period, China formed conventions on anti-Japanese patriotism and support for the front lines; Article 24 of the Constitution after the founding of the people provided the implementation of the rules of the Convention among the masses; represented by the Convention on Civilization of the Citizens of the Capital City, one after another, various localities issued the citizens convention with patriotism, law-abiding and good faith as the core, and constantly revised it in line with the progress of the national strategy. Grass-roots mass autonomous organizations also launched corresponding conventions on community civilization, villagers' codes, and advocated civilized behavior. These conventions have played an important role in improving the appearance of villages, coordinating neighborhood relations, and building harmonious communities. For example, the articles of villagers' autonomy in Zhangqiu County of Shandong Province and villages and towns in Bu Xi villages, and the villagers Autonomy articles in Ximing Yi Village in Yanling County of Henan Province, have played an important role in organizing village life. The implementation and supervision of conventions in economic management, social order becomes a sign of the maturity of social autonomy. Scholars 
point out that, unlike the general rural regulations, the villager autonomy charter is more standardized, more comprehensive, more systematic, and more authoritative. However, realizing the Maple Bridge experience under the background of the non-single system and cross-law system is still an unprecedented exploration.

\subsection{The Perspective of Unification of Legal System and Realization of Rule of Law}

The application of Maple Bridge experience in the Bay Area is not a rule of man paradigm, but an important practice to promote the development of folk norms based on the rule of law, which aims to promote the integration of civil norms in the context of a non-unitary system based on the rule of law. In general, the promotion of Maple Bridge experience needs to grasp the context of folk norms, and based on it, to promote the creative transformation and innovative development of Maple Bridge experience. From the origin, the interaction between people was originally regulated by customary law. In fact, this state of social statute reflects a kind of original democratic governance which is characterized by general public opinion, and then, with the development of the country and society, the form of unified rules has been obtained. This legal norm, which emphasizes formal justice, is, in essence, a universally recognized social norm in the long process of economic and social development. Therefore, the comprehensive promotion of the general strategy of governing the country according to law is the formal confirmation of relevant social norms constitutes, and in essence is the basis of equal protection at the level of substantive justice, as well as the standardization of the demand for the people realistic interests, which is the embodiment of the principle of people sovereignty. From the point of view of "utility function", it avoids the conflict between legal order and community system, and becomes the basis for the efficient operation of system. Meanwhile, it is also necessary for the identification of social norms that harm social welfare and the gradual replacement of non-legal norms for legal norms, which will provide normative support for a higher level of protection of rights. Therefore, with the spirit of all for the people and the attitude of openness and tolerance, starting from the unique development practice of our country, we can find a way of common development and harmonious discourse theory innovation. As early as the development stage of the traditional language and discourse theory, China has appeared the normative meaning and achieving the theory of a new system to the world. General Secretary Xi Jinping stressed the need to promote the creative transformation and innovative development of the values of the times in which China outstanding traditional culture stresses benevolence, people first, integrity, justice and harmony. The discourse of Chinese traditional culture, such as humanism, as well as a broad and profound ideological system, is of great significance for the promotion of the experience of "people-centered" Maple Bridge under the background of a non-unitary system. 


\subsection{The Perspective of Non-Institutionalized Civil Contracts and Industry Rules}

The Maple Bridge experience, which is based on grass-roots social organizations, is recognized by members of the community as a code of conduct and a custom agreement, in the protection of production and in public welfare matters. Releasing non-institutionalized civil contract and the governance effectiveness of industry rules with regional stability is the goal of bay area governance. And with the guarantee of Maple Bridge experience, it will be better implemented in practice. Non-institutionalized civil contract and trade rules are the codes of conduct and operational norms based on the consensus reached in the practice of long-term social communication and the rules of formation, which are the social association of human beings, and build up the increase of welfare and conjunctive enhancement. The form of social relations promoted by cooperation is the extension of law and morality, law and social problems, and the concrete reflection of people rights and interests in specific social forms. At the same time, the exertion of its function is based on the social attributes of human beings, and forms an industrial, regional and group governance structure. With the deepening of the process of decentralization of power, the implementation of the power list system, the social division of labor is becoming more and more refined and people life has diversified development. On the one hand, it is increasingly important to provide specific and comprehensive protection for citizens daily life, food, clothing, housing, transportation, education, employment, medical treatment, and so on, in order to realize the relevant industries, organize and standardize the management of mass organizations. At the same time, it has also become a path of rule governance for the rational adjustment of the government and the market, and between the government and the social relations. On the other hand, the urgency of safeguarding the legitimate rights and interests of employees and group members is increasing day by day. Not only is it directly related to the social organizations' development to promote the full play of social equity and justice, and the healthy development of related industries, but also affects the establishment of social stability and good fashion. From a fundamental point of view, the non-institutionalized civil contract with the goal of regional stability and the efficiency of the governance of trade rules are based on the consistency of the fundamental interests of the people, regard the freedom and all-round development of human beings as the lofty goal, and replace antagonism with harmony.

\section{Analysis of Dispute Resolution and Cooperative Governance Structure in Grand Bay Area of Foreign Countries}

\subsection{Bay Area Department Cooperative Governance}

The cooperative governance of Grand Bay abroad is mainly focused on the construction of the Bay area Protection and Development Committee and the inter-departmental cooperative governance platform, so as to effectively prevent 
the emergence of contradictions and maladies in operation. Through diachronic and synchronic combing, we can see clearly the challenges and countermeasures faced by the Bay area governance. It can be found that the San Francisco Bay area takes the performance cooperation agreement as the link point and ensures the correct application of the law by guaranteeing the participation rights and democratic decision-making rights of the member cities of the Bay area Local Government Association with its positive impact on the reform and improvement of related public services [1]. On this basis, through integrated emergency management and multiple dispute resolution paths, we can achieve the overall strategic cooperation of public services.

\subsection{Standardization of Management of Cross-Border Cooperation in Bay Area}

Foreign bay area governance focuses on the aspect of interstate agreement and judicial cooperation, but the influence of federalism on regional social conflict settlement mechanism has not been fully considered [2]. It is generally accepted that by perfecting the main body and the process of making the interstate agreement and guaranteeing the corresponding legal effect of the agreement, we can realize many public objectives, including cooperative governance and interstate cooperation. As a result, the government further strengthens the administrative agreement in the important role of interstate cooperation, and promotes the development of cross-regional dispute resolution mechanism on this basis. Taking environmental disputes as an example, Los Angeles signed the sewage treatment contract (paid share) and memorandum of air quality management area AQMD, which promoted the timely resolution of disputes and contradictions from the level of standardization [3].

\subsection{Bay Area Social Cooperative Governance}

The management of social cooperation in Bay area is a key link in the construction of dispute resolution mechanism. In China, we should grasp the special social structure, respect the people-centered development, and form all-round development social governance, including economy, ecology and society's progress. However, in foreign countries, the management of Bay area focuses on the evaluation of public-private cooperative economic benefits and the civil litigation. Especially, it emphasizes that combining with the property right system to mobilize the enthusiasm of social forces, which constitutes an important guarantee of cooperative governance. Meanwhile, it lacks the exploration for the particularity of the Bay area social cooperative governance. In addition, public-private cooperation projects are evaluated from the angle of economic risk, and the orderly development of supervision socialization practice is emphasized, understanding PPP Capital Project Risks. Among them, the most typical one is that the United States encourages the social subjects to participate in the Bay Area governance plan and a series of measures, especially emphasizing the positive 
role of releasing social synergy in the dispute resolution (incentive and preventive role) [4].

\section{The Particularity of Maple Bridge Experience Promotion in Guangdong-Hong Kong-Macau Grand Bay Area and Its Main Problems}

The core of the promotion of the Maple Bridge experience in Guangdong-Hong Kong-Macau Grand Bay Area is to solve the dilemma of cross-regional cooperative governance under "one country, two systems" (especially the problem of cross-legal cooperation governance), and to effectively prevent the behavior of circumvention of cross-legal system. Therefore, this paper focuses on the legal problems of synergy and systematicness in the promotion of Maple Bridge experience in the three places.

\subsection{The Relationship between the Central Government Overall Control and the High Degree of Autonomy}

Guangdong, Hong Kong and Macao carry the cooperation among the three regions with different legal backgrounds. The legal problems, the system problems, the cultural problems and the public opinion problems are very complex. The key relationship between the central authorities overall administration and their high degree of autonomy is on the basis of Article 2 of the basic Law of the Hong Kong Special Administrative region of the people Republic of China. At the same time, they formulate and refine the powers that belong to the central authorities, implement the central authorities overall governance over Hong Kong and Macao, and promote the integration of Hong Kong and Macao into the national development strategy. It is of fundamental significance to enhance the level of deep cooperation between Guangdong, Hong Kong and Macao, and it also constitutes the fundamental principle of solving the legal dilemma of interregional Maple Bridge experience promotion.

\subsection{The Relationship between Inter-Government Cooperation and Social Governance}

In the Bay area in the process of promoting the experience of Maple Bridge in Guangdong, Hong Kong and Macao in depth, the integration of the people support is the key factor leading to the whole body and enhancing the participation of Hong Kong and Macao residents in the construction of the Bay area. It has become an important requirement for the innovation of social governance mode. At present, the Guangdong-Hong Kong-Macao Joint Conference is mainly led by the Development and Reform Commission, and the participation of social forces is weakened. Grasping the elements of Guangdong-Hong Kong-Macau Grand Bay Area non-unitary system and cross-legal system, integrating the resources and forces of the three places, integrating the resolution of social contradictions and disputes into the functions of the economic development of the region, and putting the degree of integration of the people hearts 
and minds as the key, can deeply promote the participation of enterprises, third party environmental protection supervision, social organizations and citizens in the construction of Guangdong-Hong Kong-Macau Grand Bay Area, especially in the process of implementation of supervision. Meanwhile, we can also bring enterprises from Guangdong, Hong Kong and Macao into the Bay area Protection and Development Association and to manage them through trade membership. It can provide powerful social security for the construction of Bay area, embed the regularization, rule of law, institutionalization of dispute resolution mechanism in social integration, and stimulate the enthusiasm of all parties in the prevention and resolution of contradictions promoting Guangdong-Hong Kong-Macau Grand Bay Area Maple Bridge experience.

\subsection{The Relationship between Local Solution of Social Contradictions and Judicial Cooperation}

Under "one country, two systems", the three places of Guangdong, Hong Kong and Macao have different sources of law, which respectively apply different legal norms. Intertwined with the issue of autonomy, the problems of cross-regional Maple Bridge experience promotion are complicated and face many conflicts. One of the most intractable, that is, the use of the three different sources of law to commit circumvention behavior. In this case, it is difficult to resolve disputes effectively by only resolving contradictions in separate places. Actually, under this condition, it is very important to realize the solution of social contradictions and the effective connection of judicial cooperation. Specifically in the criminal field, the mainland of China adopts a system of statutory evidence, with the territoriality as the principal, protectionism and universal jurisdiction supplementary. Hong Kong adopts a system of free evidence, which is based on the judicial principle of following precedents with the application of the national laws of the place where the crime took place. The use of free psychological evidence and legal evidence in Macao, the prohibition of analogy, and the strict application of the principle of territoriality will possibly lead to the emergence of phenomena such as escaping from heavy sentences (fleeing to places of light punishment). Moreover, it is easy to cause unbalance between crime and punishment under the sovereignty of a unified state. In order to solve this problem, this paper integrates the existing functions of the Maple Bridge experience and judicial cooperation, and makes the promotion of Guangdong-Hong Kong-Macau Grand Bay Area Maple Bridge experience more orderly by clarifying the legal effect of the cross-regional agreement.

\section{The Specific Path and Countermeasures for the Promotion of Maple Bridge Experience in Guangdong, Hong Kong and Macau}

The integration and development of folk norms is an important breakthrough to solve the governance difficulties in Guangdong, Hong Kong and Macao. The Maple Bridge experience is based on the folk norms and self-norms that are fol- 
lowed by specific regions for the solutions of contradictions on the spot. With Maple Bridge experience, it is timely to prevent problems from happening and stop them from happening. Based on the social association of people, Guangdong, Hong Kong, and Macao, the integration and development of non-governmental norms is based on the construction of social relations that increase welfare, strengthen joint efforts, and enhance cooperation. Its fundamental and direct role in the regulation of social behavior, the regulation of social relations, and the control of social order has become an important symbol of the completeness of the normative system, the coordination of social systems, and the advancement of social civilization. And it has formed a social governance structure that includes industry, regional, and group. Under "one country, two systems", the social conflicts between Guangdong, Hong Kong and Macao are intertwined with the issue of a high degree of autonomy, which increases the complexity and difficulty of the cross-regional maple bridge experience promotion. In order to solve the dilemma of regional collaborative innovation and networked governance, we should try to protect the authority of constitution and basic law. With the standardization of rule of law approach and the promotion of Maple Bridge experience as the context, we will promote the upgrading of pan-Pearl River Delta regional cooperation to the collaborative governance pattern of Bay area of Guangdong, Hong Kong, and Macao. Based on the special reality of the non-unitary system and the three major legal systems in the Bay Area of Guangdong, Hong Kong and Macao, the integration of the people's hearts and public and private cooperation in the promotion of the Maple Bridge experience in the Bay Area of Guangdong, Hong Kong and Macao has become a deep problem. This requires the establishment of coordination mechanism based on public-private cooperation to provide guarantee for cross-regional maple bridge experience promotion, and provide intellectual support for cross regional cooperation and decision-making consultation.

\subsection{Bay Area Information Sharing Mechanism}

The timely resolution of social contradictions and disputes cannot be separated from the construction of an accurate and effective information sharing mechanism. From the point of view of essence and social attributes, it is necessary to form an effective connecting mechanism from information sharing, public participation, coordination of interests, and in-depth cooperation in order to enhance the systematic and coordinated mechanism of resolving social conflicts and disputes. As pointed out in the White Paper on the Practice of "One Country, Two Systems" in the Hong Kong Special Administrative Region, the stability and security of the Special Administrative Region cannot be separated from state support.

\subsection{Bay Area Referral and Work Interface Mechanism}

In the framework of the Constitution and the Basic Law, we will remove ob- 
stacles to institutional mechanisms, start with the establishment of a cohesive mechanism, establish a strict system of hierarchical convergence of classification and hierarchy, and form a division of labor between institutions and affairs (power and financial power) from power operation to responsibility system design (authority and responsibility unification) systematized program support. Specifically, on the one hand, it is necessary to establish a notification mechanism with the Bay Area Development Committee to promote the coordination of supervision, inspection, supervision, implementation, and accountability; On the other hand, at the level of communication, public participation, coordination of interests, and in-depth cooperation, we will seize the issues behind the issue of regional integration and development, and form synergies between governance concepts, systems, and public opinion. This also constitutes the actual guarantee of the effectiveness of the experience promotion of Maple Bridge in the Bay Area.

\subsection{Bay Area Interest Coordination Mechanism}

We will take social stability and development as the guiding principle, jointly discuss and jointly build, form a mechanism for coordinating interests of "new types of cooperation and participation in governance", and truly form a mechanism for inter-government coordination, market coordination, and social coordination. Through the organic combination of cooperation between governments and social cooperation, we will form a coordination mechanism in the Gulf Area, clarify the corresponding lists of obligations and responsibilities, and promote the corresponding innovation of risk warning and conflict prevention mechanisms. In order to realize the normalization, the rule of law, and the institutionalization of maple bridge experience promotion, it provides an important support for interlocking and coordinating the system, promotes the enhancement of the overall synergy of cooperative governance in the Bay area, and improves the effectiveness of the experience promotion of inter-district maple bridge. It should be noted that, unlike the resolution of conflicts of laws at the level of international law, the effective management of cross-border circumvention should cope with the inconsistent sources of laws. Corresponding legal norms in the three places is based on the basic premise of safeguarding national sovereignty. On the basis of this, we find the root cause of the problems in the existing social organization coordination and benefit coordination mechanisms. Under the framework of the Constitution and the Basic Law, based on respect for the autonomy of Hong Kong and Macao, we should effectively crack down on the legal obstacles to the promotion of inter-district maple bridge experience.

\section{Conclusion}

The promotion of Maple Bridge experience in Bay Area of Guangdong, Hong Kong and Macao not only faces different political and economic backgrounds, but also faces conflicts and conflicts between the three places with different 
sources of law. Under "one country, two systems", the guarantee mechanism for the promotion of the experience of Guangdong, Hong Kong and Macao Maple Bridges is centered on information sharing, benefit coordination and collaborative innovation. Guangdong-Hong Kong-Macau Grand Bay Area experience promotion is based on respecting the high degree of autonomy in Hong Kong and Macao. It is an important starting point for promoting the transformation and upgrading of Guangdong, Hong Kong and Macao deep cooperation and promoting regional integration at the level of building the rule of law. It is of great significance to the strategic docking and policy convergence of cross-regional development. Taking the opportunity of Guangdong-Hong Kong-Macau Grand Bay Area construction as an opportunity to promote the optimization of the Guangdong-Hong Kong-Macau Grand Bay Area Maple Bridge experience promotion path through the organic combination of inter-government cooperation and social cooperation, we should grasp the key factor of the fusion degree of the people hearts and minds and solve the difficult situation of governance. Through this way, we can improve the corresponding linkage mechanism to promote the integration of Hong Kong and Macao into the overall situation of national development. While the promotion of the Maple Bridge experience in Guangdong-Hong Kong-Macau Grand Bay Area is still in the process of continuous exploration and improvement, there are many problems that need to be further explored.

\section{Conflicts of Interest}

The author declares no conflicts of interest regarding the publication of this paper.

\section{References}

[1] Smith, J. and Pendelton, A. (1998) San Francisco Bay Conservation and Development Commission: Challenge and Response after 30 Years. Golden Gate University Law Review, 3, 269.

[2] Cassidy, H.A. (1974) The Environmental Protection Agency and Coastal Zone Management: Striking a Federal-State Balance of Power in Land Use Management. Houston Law Review, 5, 1152.

[3] Burris, R.W. and Rosenfeld, D.L. (1993) The Role of the Illinois Attorney General in Environmental Enforcement. Northern Illinois University Law Review, 3, 564.

[4] Cheung, M.W. (2009) Understanding PPP Capital Project Risks. European Public Private Partnership Law Review, 2, 88. https://doi.org/10.21552/EPPPL/2009/2/13 